\title{
Experimental Research: BASO Model-Based Strategic Planning Training Mediated by Training Follow up Sessions and Moderated by Transformational Leadership Impact on Mosque Organizational Effectiveness
}

\author{
Syed Jamal Abdul Nasir Syed Mohamad ${ }^{1 *}$, Roshidi Hassan² and Mohamed Zakaria \\ Mohamed Yahya ${ }^{3}$ \\ 1,2,3Faculty of Business and Management, Universiti Teknologi MARA (UiTM), 40450 Shah Alam, Selangor, Malaysia.
}

\section{ABSTRACT}

Objective - The objective of this quasi-experimental study is to examine the impact of BASO Model-Based Strategic Planning Training (as the independent variable) and Training Follow up Sessions (as the mediating variable) towards Rural Community Mosque organizational performance. This research also examines the effect of transformational leadership as a moderating factor towards mosque organizational effectiveness.

Methodology/Technique - This study uses BASO Model-Based Strategic Planning Training and is supported by Follow up Sessions. The study shows that mosque leaders can produce a comprehensive BASO model-based document outlining the strategic intentions for all four sample mosques. The present study also gathered results six months after the initial test, on the execution of the sample mosques' short-term action plans.

Findings - The empirical data demonstrates a significant contribution of technical consultancy, peer review meetings and management support as mediating factors towards mosque organisational effectiveness. Therefore, BASO model-based strategic planning training is supported by the training follow up sessions.

Novelty - This method is considered useful for implementation in Rural Mosques, within the context of FELDA, Malaysia and globally.

Type of Paper: Empirical

Keywords: Organisational Effectiveness, Strategic Planning Training, Training Follow Up, Transformational Leadership. JEL Classification: M53, M54.

\section{Introduction}

Mosque is a very important institution for Muslim communities and it is an indicator of the growth values of Islamic civilization, both in Malaysia or globally. In order to be an effective institution, the mosques are operated as not-for-profit organization (NPOs). This requires a strong focus on their strategic planning, organizational structure, organizational systems, management ability of mosque leaders, organizational developments, and leadership motivation (Cunningham, 1977; Cunningham \& Kempling, 2009; Cumming \&

\footnotetext{
* Paper Info: Received: December 12, 2016

Accepted: June 8, 2017

* Corresponding author:

E-mail: syedjamal145@uitm.edu.my

Affiliation: Faculty of Business and Management, Universiti Teknologi MARA, Malaysia.
} 
Worley, 2008). Mosques must be compelled to transform and review their to meet new challenges, particularly in response to expectations of the community, the public, and various stakeholders (Brown \& Harvey, 2006). Within Malaysia, mosques function as a place for prayers and celebrating Muslim festivals (Ahmad Zaki, 2007). Similarly, mosques function as a centre for the weekly congregation, such as the Friday prayer (Sheikh Ismail, 2008). Yusuf AL Qardhawi (2007) reveals that a mosque is not merely a place of worship; they also provide facilities for the well-being of each and every Muslim, irrespective of their cultural background or place of origin. In other words, the hospitality of the mosque extends to the local community as well as to travelers who seek refuge, and fulfill their daily prayers. Evidently, the needs of the community are fulfilled by the management of the mosque, which includes zakat collection and distribution, marriage, family disputes, welfare, propagation, education, Islamic culture centers, community centers and funeral services.

The researcher is swayed towards examining the instance of training intervention as there is a significant amount of previous studies that provide empirical evidence to suggest that strategic planning training is a prerequisite for improving the capability and capacity of mosque leaders to enhance rural community mosque organizational effectiveness. It is argued that the development of the rural community mosques is hampered by: (1) non-existence of strategic planning, (2) weak and ineffective leadership, (3) poor managerial ability among the mosque leaders, (4) poor organizational systems, (5) poor organizational structure, and (6) poor organizational development.

BASO Model-based strategic planning training is compartmentalized into the following sub-modules: (1) basic planning, (2) alignment planning, (3) scenario planning, and (4) organic planning. The BASO model itself is rated as a more comprehensive method of strategic planning as compared with other models which are mostly limited to basic goal-setting juncture. The basic BASO model-based strategic planning is considered to have a consequential effect, particularly in the transformation of mosque leaders to be more dynamic, democratic, and effective in consensual group decision-making. The second perspective of strategic planning is known as alignment planning which consists of the following elements: (1) planned strategy, (2) emergent strategy, (3) improved work process, and (4) improved organizational systems, and (5) tactical adjustment for execution plans.

\section{Methodology}

The proclivity to adopt BASO Model-based strategic planning training program, as well as the follow-up sessions based on research by Kirkpatrick, D. L., and Kirkpatrick, J. D. (2006) asserts that such training is a pre-requisite to organizational effectiveness. Furthermore, Martin, (2010) argues that the impact of training can be heightened through effective follow-up techniques. This justifies the researcher's adoption of training follow-up sessions. This present study applies an integrated adoption of four theories as the basis for the theoretical framework.

The first theory relates to the four levels of training evaluation as developed by Kirkpatrick, D. L., and Kirkpatrick, J. D. (2007; 2006) to evaluate BMSPT intervention. The training evaluation variables used in the present study include: (1) reaction, (2) knowledge, (3) behavior, and (4) results. The second theory pertains to training follow-up theory developed by Martin, (2010), which consists of the following variables: (1) peer review meetings, (2) technical consultancy, and (3) management support. The third theory is drawn from the organizational effectiveness model as postulated by Cunningham, (2009). For the present study, the theory justifies the integration of the following variables: (1) documented strategic intention, (2) structure, (3) systems, (4) managerial ability, and (5) organizational developments. The fourth theory used in the present study relates to the influence of transformational leadership as the moderating factor.

The concept of transformational leadership was initially introduced by leadership expert and presidential biographer Burns, (1978). The approach taken in the present study is quasi-experimental. Despite being a systematic inquiry, the researcher has been given four participating mosques by the FELDA management and JAKIM. The four mosques are represented by 160 participants who are required to attend a BASO Model- 
based strategic planning training program. The same set of participants also attended a series of follow-up sessions where pre-test and post-test data was collected.

In this quasi-experimental study, the effect of treatments can be measured by measuring the difference between the post-test and pre-test results $(\mathrm{O} 2-\mathrm{O} 1)$. Quasi-experimental pre-tests and post-tests are both useful means of guarding against threats to reliability and validity (Cook \& Campbell, 1979; Burrell \& Morgan, 1979; Cunningham, 1977; Smith \& Glass, 1987). This pre-test and post-test quasi-experimental study takes measurement $(\mathrm{O} 1)$ as the history of the sample before introducing the experimentation manipulation known as $(\mathrm{X})$, and followed by the manipulation measurement $(\mathrm{O} 2)$ which is the change that the manipulation has caused. The experimental effect is measured by the difference between $\mathrm{O} 2$ and $\mathrm{O} 1$. If ' $\mathrm{E}$ ' is change effect, then the equation is $\mathrm{E}=\mathrm{O} 2-\mathrm{O} 1$ (Cooper \& Shindler, 2011).

There are four time-lines or entries for data collection processes within the six-month period used. The first time-line (T1) takes place before the experimentation. The second time-line (T2), the post-test data is collected from all 160 respondents at the end of the strategic planning training program. The third time-line (T3) takes place two months after the participants completed the strategic planning training program. The research collected data on the impact of the follow-up sessions for each sample mosque at the end of the assessment month by using the second set of questionnaires (Set B questionnaire). The fourth time-frame (T4) takes place at the end of the six month period. This assessment used questionnaire Set $\mathrm{C}$ which is open-ended and closeended, comprising of pre-test and post-test criteria which are adapted from Kirkpatrick's $(1961 ; 1976)$ fourlevels of training evaluation on results.

The present study adopts a purposive sampling method which is deemed to systematically create the samples for quantitatively testing the scale items (Sekaran \& Bougie, 2013). An example of purposive sampling units are community leaders, experts, professionals known for their work with and expertise on the problem of the investigation (Babbie \& Rubin, 2009). The purposive sampling is used to justify the inclusion of rich sources of data that can be obtained to generate or test the explanatory frameworks (Patton, 2002; Gerrish \& Lathlean, 2015). Personally administered questionnaires and face-to-face interviews resulted in 100 percent of the questionnaires being returned in all four of the time-lines.

All 160 of the respondents are reliable to answer for the mosque organizational effectiveness developments, issues and problems of the rural community mosque. These sources of reliability and validity are taken into consideration in order to achieve the objectives of this investigation in terms of the adequacy of the sampling procedure. Furthermore, the judgement has to consider not only feasibility and the resource-intensiveness of alternative sampling techniques but more importantly, the overall goal of the study (Parcell et at., 1999). The research uses SPSS and SEM version 22.0 as the statistical technique. It is incumbent upon the researcher to establish that this choice is reasonable (Anderson \& Gerbing, 1988; Baumgartner \& Homburg, 1996; Wolf et. al., 2013). The study duration was six months. There were 160 respondents, which falls beyond the range of 100 and 150 suggested by Anderson and Gerbing (1988). 


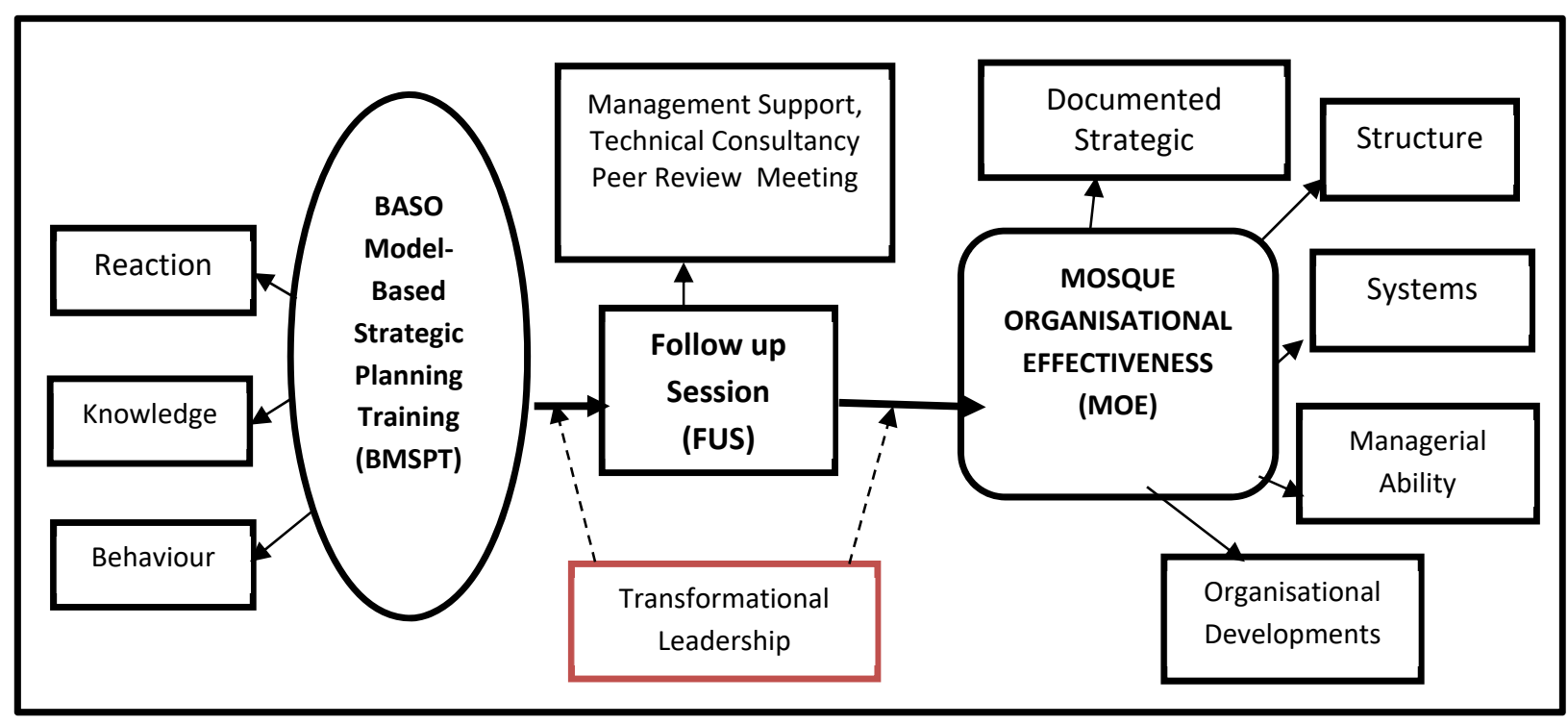

Figure 1. Research Model

\section{Results}

The results of the structural modelling reveal that with regard to the direct relationship, 17 out of 24 hypotheses tested were supported. The remaining 7 were rejected. There are nine hypotheses in which the mediating variable was supported. Of the 15 sub-hypotheses with the transformational leadership as the moderator, 6 were supported.

The results of the experiment are shown in Table 1, 2, 3 and 4.

Table 1. Summary of Measurements for the Hypothesized Model

\begin{tabular}{|l|l|r|r|r|c|}
\hline No & \multicolumn{1}{|c|}{ Structural Paths } & $\begin{array}{c}\text { Standardised } \\
\text { Coefficient }\end{array}$ & Critical Ratio & P & Results \\
\hline $\mathrm{H}_{1}$ & rea $\rightarrow$ beh & 0.233 & 1.989 & 0.047 & Supported \\
\hline $\mathrm{H}_{2}$ & $\mathrm{kno} \rightarrow$ beh & 0.603 & 4.378 & 0.001 & Supported \\
\hline $\mathrm{H}_{3}$ & beh $\rightarrow$ tco & 0.254 & 2.575 & 0.001 & Supported \\
\hline $\mathrm{H}_{4}$ & rea $\rightarrow$ tco & 0.612 & 5.730 & 0.001 & Supported \\
\hline $\mathrm{H}_{5}$ & tco $\rightarrow \mathrm{msu}$ & 0.403 & 3.358 & 0.001 & Supported \\
\hline $\mathrm{H}_{6}$ & $\mathrm{kno} \rightarrow \mathrm{msu}$ & 0.211 & 1.782 & 0.075 & Supported \\
\hline $\mathrm{H}_{7}$ & rea $\rightarrow \mathrm{prm}$ & 0.391 & 3.332 & 0.001 & Supported \\
\hline $\mathrm{H}_{8}$ & beh $\rightarrow \mathrm{prm}$ & 0.515 & 3.710 & 0.001 & Supported \\
\hline $\mathrm{H}_{9}$ & tco $\rightarrow \mathrm{prm}$ & 0.302 & 2.602 & 0.009 & Supported \\
\hline $\mathrm{H}_{10}$ & $\mathrm{kno} \rightarrow \mathrm{prm}(\mathrm{I})$ & -0.253 & -1.839 & 0.066 & Supported \\
\hline $\mathrm{H}_{11}$ & $\mathrm{msu} \rightarrow \mathrm{prm}$ & 0.036 & 0.522 & 0.601 & Rejected \\
\hline $\mathrm{H}_{12}$ & tco $\rightarrow \mathrm{dsi}$ & 0.297 & 1.708 & 0.082 & Supported \\
\hline $\mathrm{H}_{13}$ & $\mathrm{msu} \rightarrow \mathrm{dsi}$ & 0.166 & 1.806 & 0.073 & Supported \\
\hline $\mathrm{H}_{14}$ & prm $\rightarrow \mathrm{dsi}$ & -0.582 & -1.853 & 0.064 & Supported \\
\hline $\mathrm{H}_{15}$ & $\mathrm{kno} \rightarrow \mathrm{dsi}$ & 0.062 & 0.272 & 0.786 & Rejected \\
\hline $\mathrm{H}_{16}$ & rea $\rightarrow \mathrm{dsi}$ & 0.401 & 1.857 & 0.063 & Supported \\
\hline $\mathrm{H}_{17}$ & beh $\rightarrow \mathrm{dsi}$ & 0.262 & 0.942 & 0.346 & Rejected \\
\hline $\mathrm{H}_{18}$ & prm $\rightarrow \mathrm{mpe}$ & -0.027 & -0.111 & 0.911 & Rejected \\
\hline $\mathrm{H}_{19}$ & rea $\rightarrow \mathrm{mpe}$ & 0.083 & 0.501 & 0.616 & Rejected \\
\hline $\mathrm{H}_{20}$ & kno $\rightarrow \mathrm{mpe}$ & 0.389 & 2.206 & 0.027 & Supported \\
\hline
\end{tabular}




\begin{tabular}{|c|l|r|r|r|c|}
\hline No & \multicolumn{1}{|c|}{ Structural Paths } & $\begin{array}{c}\text { Standardised } \\
\text { Coefficient }\end{array}$ & Critical Ratio & P & Results \\
\hline $\mathrm{H}_{21}$ & beh $\rightarrow \mathrm{mpe}$ & 0.270 & 1.790 & 0.204 & Supported \\
\hline $\mathrm{H}_{22}$ & tco $\rightarrow \mathrm{mpe}$ & 0.017 & 0.111 & 0.912 & Rejected \\
\hline $\mathrm{H}_{23}$ & dsi $\rightarrow \mathrm{mpe}$ & 0.191 & 2.115 & 0.034 & Supported \\
\hline $\mathrm{H}_{24}$ & $\mathrm{msu} \rightarrow \mathrm{mpe}$ & -0.042 & -0.501 & 0.616 & Rejected \\
\hline
\end{tabular}

Note: 1. rea: Reaction; 2. kno: Knowledge; 3. beh: Behaviour; 4. tco: Technical Consultancy; 5. msu: Management Support; 6. prm: Peer Review Meeting; 7. dsi: Documented Strategic Intention; and 8. mpe: Mosque Performance.

\subsection{Antecedent to behaviour}

H1: The results found that there is a significant relationship between reaction (rea) and behavior (beh). This is supported as its critical ratio is 1.989 at $\mathrm{p}<0.001$ which is well above \pm 1.96 . Its path coefficient is 0.233 .

$\mathrm{H} 2$ : The result found that there is a significant relationship between knowledge (kno) and behavior (beh). This is supported as its critical ratio is 4.378 at $p<0.001$. Kirkpatrick defines the learning or knowledge level of evaluation as the evaluation of principles, facts, and techniques understood and absorbed by trainees (1959b).

\subsection{Underlying dimensions of BASO Model-based strategic planning training significantly related to technical consultancy}

H3: The result found that there is a significant relationship between behavior (beh) and technical consultancy (tco). This is supported as its critical ratio is 2.575 at $p<0.001$ which is well above \pm 1.96 . Its path coefficient is 0.254 .

H4: The result found that there is a significant relationship between reaction (rea) and technical support (tco). This is supported as the critical ratio is 5.730 which is greater than \pm 1.96 at $p<0.001$ and its standardized coefficient is 0.612 .

\subsection{Underlying dimensions of BASO Model-based strategic planning training significantly related to management support}

H5: The result found that there is a significant relationship between technical consultancy (tco) and management support (msu). This is supported as its critical ratio is 3.358 , which is more than \pm 1.96 at $\mathrm{p}<$ 0.001 . Its path coefficient is 0.403 .

H6: The result found that that there is a significant relationship between knowledge (kno) and management support (msu). This is supported as its critical ratio is 1.782 which is more than \pm 1.96 at $p<0.001$. Its path coefficient is 0.211 .

\subsection{Underlying dimensions of BASO Model-based strategic planning training significantly related to} peer review meeting

H7: The result found that there is a significant relationship between reaction (rea) and peer review meeting (prm). This is supported as its critical ratio is 3.332 , which is more than \pm 1.96 at $p<0.001$. Its path coefficient is 0.391 .

H8: The result found that there is a significant relationship between behaviour (beh) and peer review meeting (prm). This is supported as its critical ratio is 3.710 , which is more than \pm 1.96 at $p<0.001$. Its path coefficient is 0.515 .

H9: The result found that there is a significant relationship between technical consultancy (tco) and peer review meeting (prm). This is supported as its critical ratio is 2.602 , which is more than \pm 1.96 at $p<0.001$. Its path coefficient is 0.302 . 
H10: The result found that there is a significant inverse relationship between knowledge (kno) and peer review meeting (prm). This is supported as its critical ratio is -1.839 . which is above \pm 1.65 at $p<0.01$. Its path coefficient is -0.253 , which is above \pm 1.65 at $\mathrm{p}<0.01$. Its path coefficient is -0.253 .

H11: The result found that there is a significant relationship between management support (msu) and peer review meeting (prm). This is rejected as its critical ratio is 0.521 , which is below \pm 1.96 at $p<0.001$. Its path coefficient is 0.036 .

\subsection{Antecedents to Documented Strategic Intention [dsi]}

H12: There is a significant relationship between technical consultancy (tco) and documented strategic intention (dsi). This is supported as its critical ratio 1.708 which is below \pm 1.65 at $p<0.01$. Its standardized loading is 0.297 .

H13: There is a significant relationship between management support (msu) and documented strategic intention (dsi)). This is supported as its critical ratio is 1.806 which is greater than \pm 1.65 at $p<0.01$. Its standardized loading is 0.166 .

H14: There is a significant inverse relationship between peer review meeting (prm) and Mosque documented strategic intention (dsi). This is supported as its critical ratio is -1.853 which is greater than \pm 1.65 at $\mathrm{p}<0.01$. The present findings explain that having (1) too many peer review meeting sessions, (2) too many people present in the meeting and (3) too long session of peer review meeting will erode quality and productivity.

H15: There is a significant relationship between knowledge (kno) and documented strategic intention (dsi). This is rejected as its critical ratio is 0.272 which is less than \pm 1.65 at $p<0.01$. Its standardized loading is 0.062 . The respondents refer to knowledge (kno) as what they received during training as 'tacit or cognitive knowledge. BMSPT covered the first part of mosque leaders' developments which focuses more on preparing their 'mindset'. Hence, the present hypothesis is stated in an inverse manner. The second part of mosque leaders' developments through the Follow Up Session (FUS) focuses more on the formative knowledge BASO Model Strategic Planning detail processes.

H16: There is a significant relationship between reaction (rea) and documented strategic intention (dsi). This is supported as its critical ratio 1.857 which is more than \pm 1.65 at $p<0.01$. Its standardized loading is 0.401 .

H17: There is a significant relationship between behavior (beh) and documented strategic intention (dsi). This is rejected as its critical ratio is 0.942 which is less than \pm 1.65 at $p<0.01$. Its standardized loading is 0.262 . The present study found that there is no relationship between behavior (beh) and documented strategic intention (dsi) because respondents refer to behavior as a skill set that they obtain from BMSPT training more towards the cognitive part of human behavior related to motivation, teamwork culture and concept of transformational leadership, not technical knowledge of the BASO Model Strategic Planning process and procedures. The formative behavior or technical skills of BASO Model work process are obtained through technical consultations with the consultant during follow up sessions (fus) which were conducted one month after completing the BMSPT session.

\subsection{Antecedents to Mosque Performance [mpe]}

H18: There is a significant relationship between peer review meeting (prm) and Mosque performance (mpe). This is rejected as its critical ratio is -0.111 which is below \pm 1.65 at $p<0.01$. Its standardized loading is -0.027 . When comparing the present study with previous research, the findings are inconsistent. The present study shows that there is no significant relationship between peer review meetings (prm) and mosque performance (mpe). This resulted because peer review meetings (prm) significantly impacted the process of preparing the documented strategic intention (dsi) but not mosque performance. In order to justify this difference, there are two different process: (1) peer review meeting evaluations were collected during the stage 
of developing the documents of strategic planning, (2) execution of the short-term action plan started one month after completed the documented strategic intention (dsi). It is recommended that peer review meeting evaluations should be continually collected during the process of execution for mosque performance in future studies.

H19: There is a significant relationship between reaction (rea) and Mosque performance (mpe). This is rejected as its critical ratio is 0.501 which is less than \pm 1.65 at $p<0.01$. Its standardized loading is 0.083 . The findings of the present research are similar with the finding of previous research which shows there is no significant relationship between reaction and mosque performance.

$\mathrm{H} 20$ : There is a significant relationship between knowledge (kno) and Mosque performance (mpe). This is supported as its critical ratio is 2.206 which is greater than \pm 1.96 at $\mathrm{p}<0.001$. Its standardized loading is 0.389 .

$\mathrm{H} 21$ : There is a significant relationship between behavior (beh) and Mosque performance (mpe). This is supported as its critical ratio is 1.790 . which is greater than \pm 1.65 at $\mathrm{p}<0.01$. Its standardized loading is 0.270 .

H22: There is a significant relationship between technical consultancy (tco) and Mosque performance (mpe). This is rejected as its critical ratio is 0.111 which is below \pm 1.65 at $p<0.01$. Its standardized loading is 0.017 .

H23: There is a significant relationship between documented strategic intention (dsi) and Mosque performance (mpe). This is supported as its critical ratio is 2.115 which is more than \pm 1.96 at $p<0.001$. Its standardized loading is 0.191 .

$\mathrm{H} 24$ : There is a significant relationship between management support (msu) and Mosque performance (mpe). This is rejected as its critical ratio is -0.501 which is below \pm 1.65 at $\mathrm{p}<0.01$. Its standardized loading is -0.042 . The mosque leaders as respondents explained that there is weak or less involvements of the Felda Management at the Settlement level. Mosque leaders expected that the Felda Settlement management should play a more vital role in their participations and continue their engagement in teamwork processes by; (1) participating in the training session, (2) participating in the follow up sessions, (3) participating in the peer review meetings, (4) joining in the documentation strategic planning process, and (5) conveying managerial drive and motivation for execution of action plan processes.

Table 2. Summary of Statistics for All Constructs

\begin{tabular}{|c|l|c|c|c|c|c|c|}
\hline No & & Mean & SD & Items & A & Skewness & Kurtosis \\
\hline A & Documented Strategic Intention & & & 5 & 0.798 & & \\
\hline dsi1 & Complete characteristics & 5.670 & 1.136 & & & -0.846 & -0.846 \\
\hline dsi2 & Information dissemination & 5.840 & 1.043 & & & -1.196 & -1.196 \\
\hline dsi3 & Adhere to planning & 5.960 & 1.107 & & & -1.125 & -1.125 \\
\hline dsi4 & BASO model & 5.840 & 1.136 & & & -1.410 & -1.410 \\
\hline dsi5 & Planning documentation & 6.280 & 0.855 & & & -1.249 & -1.249 \\
\hline B & Mosque Performance (mpe) & & & 4 & 0.887 & & \\
\hline Ost & Organisational structure (ost) & 5.945 & 0.783 & & & -1.302 & 2.665 \\
\hline Osy & Organisational system (osy) & 5.891 & 0.920 & & & -0.947 & 0.190 \\
\hline Mab & Managerial ability (mab) & 5.846 & 0.798 & & & -2.193 & 9.331 \\
\hline Ode & $\begin{array}{l}\text { Organisational development } \\
\text { (ode) }\end{array}$ & 5.951 & 0.651 & & & -0.777 & -0.129 \\
\hline C & Reaction (rea) & & & 8 & 0.937 & & \\
\hline Gre & General reaction & 5.853 & 0.648 & & & -0.527 & 0.192 \\
\hline Oac & Objectives achievement & 5.669 & 0.701 & & & -0.749 & 0.969 \\
\hline Tme & $\begin{array}{l}\text { Training management } \\
\text { evaluation }\end{array}$ & 5.686 & 0.727 & & & -0.715 & 0.693 \\
\hline Tpe & Trainers performance & 5.920 & 0.715 & & & -0.545 & -0.242 \\
\hline Met & Methodology & 5.744 & 0.717 & & & -0.477 & 0.138 \\
\hline
\end{tabular}




\begin{tabular}{|c|c|c|c|c|c|c|c|}
\hline No & & Mean & SD & Items & $\mathbf{A}$ & Skewness & Kurtosis \\
\hline Pch & Programme characteristics & 5.846 & 0.689 & & & -0.427 & 0.011 \\
\hline Tto & Training topics & 5.766 & 0.639 & & & -0.346 & 0.112 \\
\hline Att & Attitudes & 5.951 & 0.651 & & & 0.415 & -0.129 \\
\hline $\mathrm{D}$ & Knowledge & & & 5 & 0.796 & & \\
\hline kno1 & ICT enhancement & 5.590 & 0.899 & & & -1.047 & 3.743 \\
\hline kno2 & 5S Culture & 5.820 & 0.784 & & & -0.382 & 0.306 \\
\hline kno3 & Dakwah development & 5.770 & 0.810 & & & -0.485 & -0.068 \\
\hline kno4 & Strategic planning & 5.900 & 0.762 & & & -0.002 & -0.884 \\
\hline kno6 & Management excellence & 5.880 & 0.780 & & & -0.433 & -0.033 \\
\hline $\mathrm{E}$ & Behaviour (beh) & & & 5 & 0.784 & & \\
\hline beh1 & Interpersonal skills & 5.610 & 0.825 & & & -0.379 & -0.013 \\
\hline beh2 & Public speaking & 5.760 & 0.828 & & & -0.339 & -0.334 \\
\hline beh3 & Meeting technique & 5.780 & 0.782 & & & -0.391 & -0.079 \\
\hline beh5 & Transformational leadership & 5.860 & 0.800 & & & -0.631 & 1.017 \\
\hline $\mathrm{F}$ & Technical Consultancy (tco) & & & 7 & 0.859 & & \\
\hline tcol & Appreciate technical support & 5.850 & 0.885 & & & -0.253 & -0.767 \\
\hline tco2 & Useful technical guidelines & 5.830 & 0.899 & & & -0.344 & -0.411 \\
\hline tco3 & Understand BASO model & 5.730 & 0.951 & & & -0.399 & -0.327 \\
\hline tco4 & Mosque strategic planning & 5.850 & 0.803 & & & -0.461 & -0.071 \\
\hline tco5 & Mosque effective planning & 5.640 & 0.928 & & & -0.266 & -0.534 \\
\hline tco6 & Plan of action & 5.870 & 1.026 & & & -0.877 & 0.802 \\
\hline tco7 & Development of guidelines & 6.010 & 0.978 & & & -0.925 & 0.307 \\
\hline $\mathrm{G}$ & Management Support (msu) & & & 5 & 0.863 & & \\
\hline msu1 & Working group meeting & 5.650 & 1.083 & & & -1.553 & 4.895 \\
\hline msu2 & Meeting venue and facilities & 5.770 & 1.087 & & & -1.385 & 3.935 \\
\hline msu3 & Working team evaluation & 5.860 & 0.983 & & & -1.034 & 1.396 \\
\hline $\mathrm{msu} 4$ & Resources & 5.630 & 0.963 & & & -1.109 & 3.234 \\
\hline msu5 & Complete documentation & 5.862 & 0.948 & & & -0.751 & 0.742 \\
\hline $\mathrm{H}$ & Peer Meeting Review (prm) & & & 6 & 0.862 & & \\
\hline prm1 & Strategic planning skills & 5.590 & 1.118 & & & -1.114 & 1.511 \\
\hline prm2 & Facilities and techniques & 5.650 & 1.023 & & & -0.752 & 0.689 \\
\hline prm3 & Steering committee & 5.820 & 0.924 & & & -0.696 & 0.630 \\
\hline prm4 & Charts for planning & 5.750 & 0.991 & & & -0.777 & 1.179 \\
\hline prm5 & Check A and B charts & 5.920 & 0.915 & & & -0.549 & -0.022 \\
\hline prm6 & BASO model planning & 5.280 & 0.905 & & & -0.022 & -0.502 \\
\hline
\end{tabular}

Table 2 shows that all eight constructs in the theoretical framework were rated as highly significant. Reaction was found to have the highest significance: its' Cronbach Alpha is $\alpha$ 0.937, and its' mosque performance is $\alpha 0.887$, management support is $\alpha 0.863$, peer review meeting is $\alpha 0.862$, technical consultancy is $\alpha 0.853$, documented strategic intention is $\alpha 0.798$, knowledge is $\alpha 0.796$, and behavior is $\alpha 0.784$.

Table 2 also explains that training reaction items means scores based on a Likert scale of 1 to 7 . A score of 1 indicates 'strongly disagree' and 7 is 'strongly agree'. Mean score data reveals that the highest mean score is participants attitude change (5.951) followed by trainers performance (5.920), general reaction (5.853), program characteristics (5.846), training topics (5.766), methodology (5.744), training management (5.686), and objectives achievement (5.669). 
Table 3. Summary of Results for Mediating Variables

\begin{tabular}{|l|l|l|l|c|c|c|}
\hline No & \multicolumn{2}{|c|}{ Relationships } & Mediators & Sobel Test & Results \\
\hline $\mathrm{H}_{25 \mathrm{a}}:$ & rea & $\rightarrow$ & Prm & Technical Consultancy [tco] & 3.481 & Supported \\
\hline $\mathrm{H}_{25 \mathrm{~b}}:$ & Rea & $\rightarrow$ & Tco & Behaviour [beh] & 2.536 & Supported \\
\hline $\mathrm{H}_{25 \mathrm{c}:}:$ & rea & $\rightarrow$ & prm & Behaviour [beh] & 3.692 & Supported \\
\hline $\mathrm{H}_{25 \mathrm{~d}}:$ & Rea & $\rightarrow$ & dsi & Technical Consultancy [tco] & 1.680 & Supported \\
\hline $\mathrm{H}_{25 \mathrm{e}}:$ & Beh & $\rightarrow$ & prm & Technical Consultancy [tco] & 3.634 & Supported \\
\hline $\mathrm{H}_{25 \mathrm{f}}:$ & Tco & $\rightarrow$ & dsi & Management Support [msu] & 0.807 & Rejected \\
\hline
\end{tabular}

Note: 1. rea: Reaction; 2. prm: Peer Review Meeting; 3. tco: Technical Consultancy; 4. prm: Peer Review Meeting; 5. dsi: Documented Strategic Intention; and 6. beh: Behaviour.

Training intervention is not a magic solution for organizational developments. Martin, (2007) mentions that training follow up is the important mediator to support learning transfer. Table 3 shows that technical consultancy (tco) is found to be a highly significant mediator between behavior (beh) and peer review meetings (prm) as its' Sobel Test score is 3.634, which is higher than critical ratio \pm 1.653 . Table 3 also indicates that technical consultancy (tco) is a highly significant mediator between reaction (rea) and peer review meetings (prm) as its' Sobel Test score is 3.481 which is higher than critical ratio \pm 1.653 . Technical consultancy was also found to be a significant mediator between reaction (rea) and documented strategic intention (dsi) as its' Sobel Test score is 1.680 which is more than critical ratio \pm 1.653 . However, management support as a mediator between technical consultation and documented strategic intention (dsi) was rejected as its' Sobel Test score is 0.807 which is less than critical ratio \pm 1.653 . This is because the respondents argued that they expected the Manager, Assistant Manager, Social Development Officer and Religious Development Officers at the FELDA Settlements Level to play vital roles, actively participate and get involved in the peer review meeting sessions and the decision-making process.

In Table 4, the first supported hypothesis is that transformational leadership (tle) moderates the relationship between behavior (beh) and technical consultancy (tco) as Constrained CMIN $(\chi 2) 3322.360$ and degree of freedom is 1673. Unconstrained CMIN ( $\chi 2) 3319.613$ and degree of freedom is 1672 . Whereas, $\Delta \chi 2=2.747$ and $\Delta \mathrm{df}=1$.

The second supported hypothesis is that transformational leadership (tle) moderates the relationship between peer review meeting (prm) and documented strategic intention (dsi). Status for the Constrained CMIN $\left(\chi^{2}\right)$ at 3324.057, degree of freedom (df) score is 673. Unconstrained CMIN ( $\left.\chi^{2}\right)$ at 3319.613, degree of freedom (df) score is 672. Whereas $\Delta \chi 2=4.444$ and $\Delta \mathrm{df}=1$.

The third supported hypothesis is that transformational leadership (tle) moderates the relationship between reaction (rea) and documented strategic intention (dsi). Status CMIN $(\chi 2)$ for Constrained value at 3326.370, Degree of Freedom (df) at 1973. CMIN (f $\chi 2)$ for Unconstrained at 3319.613, degree of freedom 1972. Status for $\Delta \chi 2=6.757$ and $\Delta \mathrm{df}=1$.

The fourth supported hypothesis is that transformational leadership (tle) moderates the relationship between knowledge (kno) and mosque performance (mpe). Calculated status for Constrained CMIN ( $\left.\chi^{2}\right)$ at 3323.018, Degree of Freedom (df) at 1673. Unconstrained CMIN ( $\chi 2), 3319.613$, degree of freedom at 1672 . Whereas, $\Delta \chi 2=3.338$ and $\Delta \mathrm{df}=1$ 
Syed Jamal Abdul Nasir Syed Mohamad, Roshidi Hassan and Mohamed Zakaria Mohamed Yahya

Table 4. Summary of Direct Relationships Moderated by Transformational Leadership (tle)

\begin{tabular}{|c|c|c|c|c|c|c|c|c|c|c|}
\hline \multirow{3}{*}{$\begin{array}{l}\text { No } \\
\mathrm{H}_{26 \mathrm{c}}:\end{array}$} & \multirow{2}{*}{\multicolumn{3}{|c|}{ Constructs }} & \multicolumn{2}{|c|}{ Constrained } & \multicolumn{2}{|c|}{ Unconstrained } & \multicolumn{2}{|c|}{ Difference } & \multirow{3}{*}{$\begin{array}{c}\text { Results } \\
\text { Supported }\end{array}$} \\
\hline & & & & \multirow{2}{*}{$\frac{\chi^{2} \mathrm{c}}{3322.360}$} & \multirow{2}{*}{$\begin{array}{r}\mathbf{d f}_{\mathbf{c}} \\
1673\end{array}$} & \multirow{2}{*}{$\begin{array}{c}\chi^{\mathbf{2} u} \\
3319.613\end{array}$} & \multirow{2}{*}{$\begin{array}{c}\mathbf{d f}_{\mathbf{u}} \\
1672\end{array}$} & \multirow{2}{*}{$\begin{array}{c}\Delta \chi^{2} \\
2.747 \\
\end{array}$} & \multirow{2}{*}{$\frac{\Delta \mathbf{d f}}{1}$} & \\
\hline & Beh & $\rightarrow$ & Tco & & & & & & & \\
\hline $\mathrm{H}_{26 \mathrm{~m}}$ : & Prm & $\rightarrow$ & Dsi & 3324.057 & 1673 & 3319.613 & 1672 & 4.4 & 1 & $\mathrm{Su}$ \\
\hline $\mathrm{H}_{26 n}:$ & Rea & $\rightarrow$ & Dsi & 3326.370 & 1673 & 3319.613 & 1672 & 6.757 & 1 & Supported \\
\hline $\mathrm{H}_{260}$ : & Kno & $\rightarrow$ & Mpe & 3323.018 & 1673 & 3319.613 & 1672 & 3.338 & 1 & Supported \\
\hline $\mathrm{H}_{26 \mathrm{p}}$ : & Beh & $\rightarrow$ & Mpe & 3322.336 & 1673 & 3319.613 & 1672 & 2.723 & 1 & Supported \\
\hline
\end{tabular}

\section{Conclusion}

The results provide that BASO Model-Based Strategic Planning Training, Training Follow up sessions, and Transformational Leadership are the important pre-requisites for improving the performance of rural community mosques. The present study also evaluated six months post-test results on the execution of sample mosques' short-term action plans. The empirical data shows there is significant contribution of technical consultancy, peer review meetings and management support as mediating factors towards mosque organizational effectiveness. Therefore, the BASO model-based strategic planning training supported by training follow up sessions is reliable for use in Rural Mosques, particularly in the context of rural mosques in Malaysia as well as other countries.

\section{Acknowledgements (Optional)}

The authors gratefully acknowledge the help of the University of Technology MARA of Malaysia and the Ministry of Higher Education (MOHE) of Malaysia in providing the Fundamental Research Grant Scheme (FRGS Project Number: UiTM 136/2015) and Federal Land Development Authority (FELDA), and Department of Islamic Development Malaysia (JAKIM).

\section{References}

Ahmad, Z. (2007). Pengurusan masjid secara professional [Professional mosque management]. Yayasan Islam Hadhari Malaysia. UiTM.

Anderson, J. C., \& Gerbing, D. W. (1988). Structural equation modelling in practice: A review and recommended twostep approach. Psychological Bulletin, 103(3), 411-423.

Babbie, E., \& Rubin, A. (2008). Research methods for social work. Belmont, CA: Wadsworth/Thomson Learning.

Baumgartner, H., \& Homburg, C. (1996). Applications of structural equation modeling in marketing and consumer research: a review. International journal of Research in Marketing, 13(2), 139-161.

Brown, D. R., \& Harvey, D. F. (2006). Organizational change: an experiential approach to organization development. Pearson Prentice Hall.

Burrell, G., \& Morgan, G. (1979). Sociological paradigms and organizational analysis. Heinemann Press. 1-37.

Burns, J. M. (1978). Leadership. New York. NY: Harper and Row Publishers.

Cook, T. D., \& Campbell, D. T. (1979). Quasi-experimentation: design and analysis issues for field settings. Boston: Houghton Mifflin.

Cooper, D. R., \& Shindler, S. P. (2011). Business research methods. 11th ed. McGraw-Hill International Edition.

Cummings, T., \& Worley, C. (2008). Organizational development and change. 9th ed. Cincinnati, OH: Southwestern College,

Cunningham, J. B. (1977). Approach to the evaluation of organizational effectiveness. Academy of Management Review, 2(77), 463 - 474. University of Victoria. Available from http://ebscohost.com

Cunningham, J. B., \& Kempling, J. S. (2009). Implementing change in public sector organizations. Management Decision, 47(2), 330-344. 
Gerrish, K., \& Lathlean, J. (2015). The Research Process in Nursing. 7th ed. Wiley-Blackwell.

Kirkpatrick, D. L., \& Kirkpatrick, J. D. (2006). Evaluating training programs: The four levels, 3rd ed. San Francisco, CA: Berrett-Koehler Publishers

Kirkpatrick, D. L., \& Kirkpatrick, J. D. (2007). Implementing the four levels: A practical guide for effective evaluation of training programs. San Francisco, CA: Berrett-Koehler Publishers.

Martin, H. J. (2010). Improving training impact through effective follow-up: techniques and their application. Journal of Management Development, 29(6), 520-534; 29(6). Cleveland State University. Ohio, USA: Cleveland. doi: 02621711. Available from http://H.MARTIN@csuohio.edu.

Parcell, C., Stommel, M., \& Hubbard, R. P. (1999). Mismatch of classroom furniture and student body dimensions: empirical findings and health implications. Journal of Adolescent Health, 24(4), 265-273.

Patton, (2002). Qualitative research \& evaluation methods. 3rd ed. California: Sage Publications. doi: 0: 0761919716.

Sekaran, U., \& Bougie, R. (2013). Research Methods for Business, A Skill-Building Approach. John Wiley.

Sheikh, I. (2009). In JAKIM 'Seminar High Priest (Imam) Malaysia', November 22, 2009; cited by Ghafani Awang Teh, KESUMA Department, JAKIM, June 2013.

Smith, M. L., \& Glass, G. V. (1987). Research and evaluation in education and the social sciences. New Jersey: Prentice Hall.

Wolf, P. J., Kisida, B., Gutmann, B., Puma, M., Eissa, N., \& Rizzo, L. (2013). School vouchers and student outcomes: Experimental evidence from Washington, DC. Journal of Policy Analysis and Management, 32(2), 246-270.

Yusuf Al Qardhawi, (2007). ‘al-Dīn wa-al-siyāsah, ta'ṣīl wa-radd shubuhāt', Cairo. Dār al-Shurūq. doi: 977-09-1971-3. 